\title{
The Citadel Itself: Defending Semantic Internalism
}

Elliot Murphy ${ }^{1,2}$

1. Vivian L. Smith Department of Neurosurgery, McGovern Medical School, University of Texas Health Science Center, Houston, Texas, 77030, USA

2. Texas Institute for Restorative Neurotechnologies, University of Texas Health Science Center, Houston, Texas, 77030, USA

\begin{abstract}
:
Semantic internalism is the view that linguistic meaning amounts to forms of conceptual instructions, and that the process of forming linguistic representations does not involve reference to extra-mental entities. Contemporary philosophy of language remains predominantly externalist in focus, having developed systems of extensional reference which depart from classical rationalist assumptions. I will defend semantic internalism using a broad range of case studies, accruing what $I$ see at the most convincing arguments in its favour. Particular focus will be placed on exemplar cases such as natural kind and artifactual terms. Copredication via inherent polysemy will be used as a strong source of evidence for internalism, countering the received view of the externalist character of meaning. Overall, my aim is to comprehensively defend internalism against its critics and to push the exploration of linguistic content and meaning "back into the brain".
\end{abstract}

Keywords: Internalism. Externalism. Polysemy. Copredication. Concepts

Author note: Correspondence concerning this article should be addressed to Elliot Murphy (elliot.murphy@uth.tmc.edu). 


\section{Introduction}

"Despite 2,400 years or so of trying, it is unclear that anyone has ever come up with an adequate definition of any word whatsoever, even the simplest" (Elbourne 2011: 1). "[I]t is a very difficult matter to describe the meaning of a word" (Chomsky 2000: 61).

Darwin wrote in his Notebook $N$ in 1838, aged 29, that "[t]he study Metaphysics, as they have always been studied appears to me like puzzling at astronomy without mechanics.Experience shows the problem of the mind cannot be solved by attacking the citadel itself.The mind is a function of body" (cited in Gould 1975: 125). Darwin's recommendation for the naturalistic study of mind-that it should not sideline "mechanics" of lower-level implementation - should carry over to the investigation of more specific forms of cognition, such as the nature of linguistic meaning. Any account of linguistic meaning must be cognitively plausible and able to be accommodated by the science of language use and representation, in a similar manner that philosophy of physics should not become divorced from physics.

In order to approach this issue, I will here be defending an already-formed, wellarticulated position in philosophy of language against its critics: semantic internalism. This is sometimes called the biolinguistic approach to lexical reference, whereby "there are no independently specifiable external physical objects that correspond to the referential expressions we use" (Hinzen 2007: 21). Semantic internalism, to put it plainly, investigates internal states. It studies the organism in abstraction from the complexities of the social, physical and cultural environment. Successfully expressing a concept is something an individual is responsible for, not someone else or some extra-mental feature; to borrow a formulation, we are all the "masters of our meanings" (Braddon-Mitchell 2004). As such, the claim that linguistic objects like the lexical item 'water' derive their meaning internally is to say that they do not derive their meaning through the organism achieving some internal approximation to a feature of the environment. That is, the claim of the semantic internalist is that 'water' is not part of the extra-mental world that we become accustomed with, it is rather a mind-internal representation that we impose on sensory evidence during worldy interactions.

The majority of working philosophers identify as externalists (Gertler 2012), exploring word-world and alethic constructs. Putting it somewhat simplistically, externalists posit "the concept of water" while internalists posit a "water-concept"; the former us used to denote some invariant extra-mental object, while the latter just is the representation under discussion that can then be used, in a given context, to denote some variable property of the sensorium or 
imaginative state. I will be marshalling what I see as the most compelling evidence for semantic internalism, with specific reference to single-word reference and complex polysemy.

\section{Words and Actions in Referential Semantics}

A common, naïve intuition transferred into philosophy of language is the idea of reference: that words refer to entities, qualities and events in our sensorium and are directly related - via some connection - to the external world. Claims about the existence of languageworld isomorphisms go back very far; in the modern era, most prominently to Kant, Bolzano and early Wittgenstein, where the idea that a mind-internal representation can exhibit an isomorphism with the thing representated is articulated. More recently, we find the Davidsonian view that the compositionality of meaning can be accommodated only via postulating truth-conditions for sentences, and referents for words (Davidson 1984).

Reference is not a pre-theoretical notion (as discussed by Ludlow 2003). It is a theoretical term that works differently in different contexts. The closest usage that approximates cognitive plausibility, and the actual functioning of natural language, is one that falls outside of externalist 'possible worlds' semantics and connects with ordinary language use: Reference is an action, as Strawson (1950) and Chomsky (2000) notably argue, in defence of a type of 'use theory of meaning'. In contrast, linguistic meaning itself is an inference, guided by perception. As such, we could also use the term 'reference' to denote the process through which individual lexical items can be used to search mind-internal conceptual domains to generate inferences/representations. Both of these usages (the action of referring by an individual, and the subsequent mind-internal 'fetching' of a concept) form the basis of semantic internalism. Roots of these ideas - of mapping linguistic forms to semantic interpretations - in modern thought can be traced to Katz and Fodor (1963) and Jackendoff (1972). The action of referring also involves (at least) the speaker, the utterance, the context, and some properties of the external world, where 'the speaker' refers to the suite of cognitive resources (including language-external cognitive systems) they bring to the occasion of reference, and 'properties of the external world' denotes Humean sense data and phenomenology (or related formulations) — far beyond a simple word-object relation.

Semantic internalism could be argued to have been the dominant position in philosophy of language for centuries, until the latter half of the twentieth century. Traditional 'analytical philosophy' was essentially internalist in character, from the work of Frege to Gödel to Ayer 
to Chrisholm (Johnson \& Leslie 2012). Only relatively recently has externalism been substantively defended (Putnam 1975, Burge 1979, Kripke 1980); Smith (1992) regards the question of how language is "used to represent the world" as the primary concern of (externalist) philosophers of language.

In what follows, I will review some of the core externalist arguments and, in parallel, some major internalist concerns. An essay aiming 'for internalism' is quite different than one geared 'against externalism'. I will mostly aim for the former, in an attempt to show that the acts underlying lexical reference involve and are constrained by a range of cognitive processes. Critical reviews of existing externalist arguments will not be the focal point of what follows (for such an approach, see Valente 2019), though they will at times be presented in the context of the positive project of building a cognitively plausible model of lexical content. I will also focus mostly on lexical meaning, though some cases pertaining to the more complicated issue of structural/sentential meaning will be noted too.

\section{The Region of Myth and Symbol}

"His own opinion, which he did not air, is that the origins of speech lie in song, and the origins of song in the need to fill out with sound the overlarge and rather empty human soul". (Coetzee 2000: 4).

To couch our discussion in terms more familiar to linguists: "It is not that speakers communicate because they have an E-language in common; rather, where I-languages overlap sufficiently, communication is possible” (Hornstein \& Anthony 2003: 9). The 'I-' connotes intensional, internal and individual, while the 'E-' connotes extensional and external(ist) (although he ultimately comes to externalist conclusions about the possibility of languageworld relations, Ludlow notes that "there are no such things" as E-languages in the context of coherent objects of linguistic inquiry; Ludlow 2003: 143). The same is true for linguistic semantics. Grammars between speakers can overlap, and so can conceptual representations; there is no reason to assume that human semantic representations differ drastically across speakers. According to internalism, there are only individual I-languages and conceptual systems that take the instructions sent to them by syntax to construct a particular representation, informed and influenced by context of use and other pragmatic considerations. 
Likewise, the meaning of a stop sign is different from the meaning of the phrase 'a stop sign': only the latter involves combinatorial composition to derive a hierarchically structured meaning. There are many other intricacies of language which are often sidelined when discussing philosophy of language. Consider how syntactic headedness and semantic headedness typically map biunivocally onto each other (Piatelli-Palmarini 2020), with close ties existing between syntactic structure and interpretation (Hinzen 2006). 'Red boat' is a Noun Phrase, and it is a boat that is red, not a red quality with boat-like features. Yet there are exceptions: with 'former lawyer' or 'alleged threat', the adjective syntactically modifies the noun, but semantically they involve modifying the adjectival phrase (a former lawyer is not a lawyer).

By definition, this I-language perspective requires that the generative component yields particular intensions - nothing ever leaves the confines of the language faculty, save the routine interface with language-external cognitive systems. For example, the language faculty encodes mass-count grammatical features, which map to the broader substance-object conceptual division. Natural language ontology can also expose certain properties of language-external conceptualizations (Wellwood et al. 2018). Meanwhile, semantic internalists often assume the lexicon to be composed of phonological, semantic and grammatical features: the first two types for articulation and interpretation, and the third type seemingly just for the generative component itself. Certain features will be important for interpretation, while others will be important for forming particular syntactic relations. This view is in sharp contrast to one of the various externalist arguments that language is a purely social phenomenon, a kind of practice, based on "a social custom" (Dummett 1986). For Lange (1957: 77), by using language to describe objects, "[t]he name is made a thing, but a thing having no similarity with any other thing, and to which, in the nature of human thought, only negative predicates can be attached. But since there is an absolute necessity for some positive assertion, we find ourselves from the outset in the region of myth and symbol".

Ignoring many important historical details, we can roughly summarize that nineteenthcentury philologists stressed the importance of sounds; by the 1920s, Otto Jespersen shifted attention to the written word; in the 1950s, Chomsky moved the study of language towards abstract mental structures, beyond any specific form of input modality. By the 1970s, Tarskian systems of 'semantics' and truth-conditions had been developed to a sufficient degree of sophistication, but a false conclusion was made: Natural language has meaning; meaning is a system of semantics; semantics can be represented via Tarskian models; therefore, the 
semantics of natural language is Tarskian. While one can readily model a system of semantics via Tarski-style truth-conditions, it does not follow that the meanings we derive from natural language expressions (and not formal language expressions) follow the same 'externalist' system of reference, whereby one symbol denotes some other entity (Higginbotham 1990). Perhaps this is one of the reasons why the twentieth century was "the silliest of all the centuries, philosophically speaking (for all its achievements)" (Strawson 2008: 8).

Other historical accidents conspire here. Philosophy of language is usually conducted in English, which is a language that likes to nominalize indiscriminately: things are named, events are named, abstract relations are named. Even the word 'object' itself has an unavoidably “chair-like feel”, as Strawson (2009: 545) notes. 'Reference', 'belief', 'desire', and other such terms are borne out of common sense, ordinary use of the English language, and there is no logical reason why they should map onto postulates of any explanatory scientific theory, any more than our ordinary use of words like 'energy' and 'force' should have to find a home within contemporary theories of physics.

Consider how any polity concept invites joint contributions from concrete concepts and abstract concepts: the city of Liverpool can be 'fun' and 'polluted', and can be burned down and re-built on the opposite side of the Mersey river, yet still be called Liverpool. The city does not so much have a function as it is a function; or, it is a way of physically realizing (in whatever form or shape it takes) a particular functional notion. The same is even true of much less complex objects, like a lunch, which can be 'delicious' but also 'delayed' at the same time, with no object in the external world being able to simultaneously host these properties. There is scant empirical research into the internal structure of these concepts, and what we do seem to know about, for instance, the individuation criteria for institutional words (organizationbased words like city, town, library, newspaper) points to the prominent role of functionality over materiality (Murphy 2021b).

Consider further world-defying constructs. Think of a library: If John reads every book in the library, and then burns the whole place down, he has burned more books than he has read if the library contains multiple copies of certain books. This supposed paradox in quantification immediately leads to a problem for any traditional model of reference (Chomsky 2000). As covered extensively in Ludlow (2014), words like book can have their meanings openly extended to new usages, like when a book can be said to be 'physically' on a memory stick 
(e.g., in PDF form). The same referential ambiguity applies to other PHYSICAL-INFORMATION composites, like movies and games.

(1) a. Mary thought the movie was thrilling and put it back on the shelf.

b. John said that Disco Elysium was quick to download and worth the wait.

Different factors presumably influence individual judgements about these cases. However, the more immediate point is that physical constitution only plays a role in determining case-by-case reference, rather than being the determining factor. This appears to undermine the prospects for referentialism.

These observations clash with many notable claims in the literature. Lepore (2001: 197) writes in an essay on Donald Davidson: "Tables, chairs, and people are concrete, dated particulars, that is, unrepeatable entities with location in space and time. These features alone distinguish them from, say, either numbers or God". Likewise, Hoffman and Rosenkrantz (2003: 46) contend: "The distinction between abstract and concrete is, we believe, a fundamental distinction, in that every entity is either concrete or abstract, and no entity is both. We believe that the abstract-concrete distinction is, in fact, the most fundamental categorical distinction". Then there is Hempel's (1950) empiricist criterion of meaning, which honoured the spirit of logical positivism by claiming a statement to be meaningful if and only if it admitted itself to experiential test. Consider also Juhl and Loomis's (2010: 270) introduction of the term 'analytic*' to stand for a sentence-as-used and understood by a linguistic community, "a common form of stipulation", though this is tantamount to a new construction of the E-language concept of public languages that does not easily fall within naturalistic scope. Meanwhile, Lewis (1975) believed that "meaning" is to be found in the related notion of "conventions", or regulated forms of verbal behaviour, treating language not as a natural biological object but rather studying it as a form of sociolinguistics or game theory, hence not contributing to our understanding of natural language computation.

These ideas are at odds with the internalist perspective, that linguistic meaning is formed by a mind-internal computational system generating lexical items and hierarchically organized sets of syntactic objects that are accessed by language-external conceptual systems for interpretation. Verbal conventions cannot explain why "The lawyer called the politician from Texas" can mean that the call or the politician are from Texas, but cannot mean that the lawyer is from Texas. Governing rules of syntactic computation are needed, not regularised behaviour. This is important to stress since many components of the major alternative- 
semantics-pragmatics, and 'what is said' - are not natural objects of inquiry (i.e. much like the theme of 'communication', it needs to be decomposed into finer-grained processes and primitives; Murphy 2020a), although pragmatic processes play a major role in the act of reference and many such processes are indeed becoming more fine-grained, and compatible with general, efficient inferential processing (Carston 2004). Argument structure and thematic roles play a crucial part in human meaning (Hinzen 2007) - although they do not exhaust its content, since we still need some atomic, invariant representation of Hamlet before we can merge him into a noun phrase - and are ultimately syntactic in nature. If thematic structure was all there was, then the Jabberwocky's 'toves' and 'book' would both have the same atomic linguistic meaning and it would simply be pragmatics that enrichens the rest, which is plainly not the case given the intricacies of 'book'.

The standard assumption in much of contemporary philosophy of language is that a proper name is merely a label for a (mind-independent) thing, and that the meaning of names derives precisely from what this thing is (its physical nature/constitution). As such, the name is assumed to become meaningless if it turns out that there is no such thing that it was meant to label, leading to apparent paradoxes. But this has things backwards: the Ship of Theseus has a meaning (a lexico-semantic representation, seemingly structured around a paradigmatic or prototypical sense of shiphood) independent of whatever state the world happens to be in; see also Kripke's (1979) puzzle.

Putting this more concretely, ships can have all their parts replaced and still remain the same 'ship', just as the discarded parts can be rearranged into a new 'ship'. This can readily be understood by any language user (including Trigger from Only Fools and Horses, who claims to have owned the same haircomb for decades, despite the fact that he often replaces its handle and head). For Hume, ships and houses "endure a total change, yet we still attribute identity to them, while their form, size, and substance are entirely alter'd" (1978: 257). The Theseus and Sorites paradoxes are inherently graded - but it is the concepts of 'ship' and 'sand heap' which are graded, not the external world itself. There is nothing in the world which could fully satisfy our complex concepts of house, river, ship - the concepts are complex enough to be appropriately applied to a number of scenarios. Philosophical thought experiments are one way that we can expose the properties of lexical items; as Hinzen (2006: 66-67) notes: “An object shows its true nature not by exploring its natural and holistic connections with other things, but by putting it in an artificial circumstance where it establishes accidental and 'unnatural' connections with other objects". The "mythical logically proper name" (Strawson 1950: 340) 
remains just so: Reference "is not something an expression does; it is something that some one can use an expression to do" (Ibid. 326). It at least seems to be the case that every use of a linguistic expression carries a great deal of contextuality of use: focusing purely on lexical content will be insufficient for establishing successful reference. As such, the semantic internalist concludes that the act of referring is a suitable topic for pragmatics (neo-Gricean perspectives; relevance theory), but not formal semantics.

\section{I-Semantics and I-Language}

"The question young David raises is an important one. What does it mean to be an orphan? Does it simply mean that you are without visible parents? No. To be an orphan, at the deepest level, is to be alone in the world." (Coetzee 2020: 5)

One of the direct corrolaries of assuming an internalist perspective is that the generative component of language interfaces with mind-internal conceptual systems (Pietroski 2018). Consider 'water'. This is loosely defined as a physical entity $\left(\mathrm{H}_{2} \mathrm{O}\right)$ by externalists, considered to be a rigid designator; as such, the meaning of the word 'water' determines an extension for it, with the extension being the set of water substances, which are composed of $\mathrm{H}_{2} \mathrm{O}$ plus some impurities. It seems more accurate to characterize the lexical meaning of 'water' as a functional concept, which is weighted to a certain degree (though not entirely) by its physical constitution (indeed it may turn out that shared conceptions of 'water' are mostly grounded in our shared concept of physicality $/ \mathrm{H}_{2} \mathrm{O}$, but the point here is that this is not the sole determinant). Some European travellers crossing the Congo in 1648 were so famished and starved that they were forced to "drink water [which] resembled horse's urine" (Braudel 1992: 227). No doubt a chemist would reject the notion that the substance from the River Thames is water (or rather 'water defined as $\mathrm{H}_{2} \mathrm{O}$ '). As Underhill (2009: 41) puts it, words "do not bear any fixed relation to any actual physical thing in the world".

We also find the "super-externalist" (Ludlow 2003: 149) position that linguistic form can only be determined via a complete ontology (i.e., 'water' would get its meaning via a total decomposition of $\mathrm{H}_{2} \mathrm{O}$ ). Another such implementation of this perspective is found in Meinong (1904), who assumed that all expressions refer, and that it follows from this that there must be such things as non-existent objects in the world. For instance, if "John seeks the Golden Mountain" is deemed true, then there must be a non-existent object that the expression "the Golden Mountain" refers to (see Russell 1905). 
The semantic internalist rejects the claim that words in ordinary natural language refer to extra-mental entities - unlike postulates in naturalistic theories, like the protein titin, which has over 180,000 letters and takes over three hours to pronounce, and is surely not part of any 'language' in the ordinary sense of cognitive science and linguistics. On the other side, we have the externalist, who maintains that the meaning of words are determined by extra-mental properties. But is the externalist therefore also committed to the reverse claim (which seems to follow logically) that the extra-mental world contains entities which correspond to mindinternal lexical representations (after all, this is just the alternative way of phrasing the standard externalist claim that "meaning isn't in the head")? Further, it does not seem to have been made clear which aspects of the world it is that language is supposed to refer to: do the externalists assume all of the world can be referred to, and if not, why not? Consider also Hinzen's (2006, 2007) critique that the externalist reference-relation is ultimately non-explanatory: positing it does not aid our understanding of linguistic structure.

Perhaps just as relevant here is Russell's (2003) invitation for us to consider a blind physicist who knows all of physics (i.e., in some hypothetical physics-complete scenario). What is it that a sighted person knows that the blind physicist does not? Certain experiential content - what it is like to see the colour red — is not a part of the blind physicist's knowledge; physics can only capture "the causal skeleton of the world". We can at least conclude from this that my experience of seeing the color red just is a property of the world, but one we cannot provide any naturalistic account for.

Departing from super-externalism, the more moderate and common externalist claim that water is $\mathrm{H}_{2} \mathrm{O}$ plus impurities also does not succeed in the following case (Chomsky 2000): A tea factory explodes, contaminating the local water supply. What comes out of my tap is very slightly contaminated with the substance from the tea leaves in the water supply, but it is still water. Meanwhile, a chemically identical substance is being made a few blocks away in a neighbourhood with a clean water supply, when someone makes a cup of tea with the same concentration of tea chemicals. My substances is water, theirs is tea. The word 'water' does not refer to some extension; it has only an intension, an internally generated representation that can be used by people to denote certain elements of their sensorium, and which also has certain individuation criteria. Hence, the meanings of (2a) and (2b) are not equivalent.

a. That is water.

b. That is a sample of $\mathrm{H}_{2} \mathrm{O}$, modulo some impurities. 

has a higher percentage of $\mathrm{H}_{2} \mathrm{O}$ than "the stuff from my well". He adds that "Diet Sprite ${ }^{\circledR}$ and club soda are even more like $\mathrm{H}_{2} \mathrm{O}$ " yet are not deemed water for reasons to do purely with “intended purposes”. Descartes's 'Comments on a Certain Broadsheet' (1984) also made a distinction between the scientific definition of the sun and the commonsense concept sun, seemingly in line with this view. Pietroski (2018) maintains that denotational acts, of the kind involving complex polysemy, cannot be explained purely by semantic knowledge, and involve a range of intricate pragmatic rules. For rough approximation, Ludlow (2003) makes a distinction between I-substances (water) and P-substances $\left(\mathrm{H}_{2} \mathrm{O}\right)$, which refer to intensions and physical entities, which can be shown to diverge considerably.

Consider next the Twin Earth thought experiment (Putnam 1975). In some parallel universe, it is said that water is not made of $\mathrm{H}_{2} \mathrm{O}$ but rather some other substance, XYZ: Can the inhabitants of this Twin Earth use 'water' to refer to this substance? Putnam says 'No'. The internalist project in semanitics says 'Yes', because 'water' seems to be polysemous between some more common, function-based sense, and a more concrete, technical sense. Indeed, imagine some other parallel universe: Pietroski (2017) offers Fraternal-Earth, where doppelgangers of our scientists discover that what they have all been loosely calling 'mud' in fact has a deep, uniform chemical structure. All forms of 'mud' are of substance XYZ, hence they can use the concept 'mud' to refer successfully to all physical structures of 'mud'. But it does not follow from this that the inhabitants of Fraternal-Earth could not have used 'mud' to refer to our chemically-diverse samples of mud, if they entered a black hole and ended up in the English countryside. The idea that their 'natural kind'-conforming use of 'mud' could not readily be extended to a polysemous (function-informed) sense is not well-supported. Hence, we can use simple words like 'water' and 'mud' to access multiple concepts.

The Twin Earth thought experiment is "generally thought to give considerable support for semantic externalism: the view that the meaning and extension of some linguistic expressions, in particular natural kind terms, are at least partly dependent on factors external to the individual speaker" (Haukioja et al. 2020). Putnam agrees with the internalists that words in and of themselves do not refer, but maintains that our intuitions about how words can refer are constructed via person $X$ referring to object Y using sign $S$ (1992: 382); which presupposes some mind-independent structure for object $\mathrm{Y}$, which the mind, in turn, needs to become acquianted with to subsequently use a word to refer to it, which simply begs the question of how words relate to any notion of objecthood. 
Moving beyond these examples, Kripke (2019) provides a rejoinder to Dummett's social use of natural kind terms, and also Putnam's externalism vis-à-vis its treatment of linguistic division of labor, whereby part of our meaning of the word 'gold' lies in our deference to experts to provide an explanation for some chemical basis. Though Kripke uses the following argument to defend a version of externalism (somewhat modified from Kripke 1980), for our purposes it serves to highlight what the semantic internalist would see as the inherent polysemy in terms like 'gold'. Kripke notes that 'gold', like water, can be said to be 'really' composed of the chemical element Au. Imagine that all of the world's gold experts (i.e., those who can distinguish gold from fool's gold) are invited to a conference in a large convention center, and are all killed in an explosion. Kripke (2019) asks: Does it follow that the extension of gold now encompasses fool's gold, since there is nobody around to tell the difference? If we assume that 'gold' has no such extensions to begin with, we have no problem. The crucial factor that Kripke does not enter into discussion here is the background knowledge of the people he is presenting this argument to. It is already too late, so to speak, for the person Kripke is presenting this argument to (i.e., his audience) for them to somehow remove their pre-existing modification of the representation of 'gold' back to its mere functional sense, removing what Ludlow would term the P-substance sense from their lexical entry for 'gold'. The audience is already knowledgeable that 'gold' can be used to refer to some chemical composite. For the rest of the people inside Kripke's scenario-such as the news reporters videoing the aftermath — their conception of 'gold' remains the same.

In contrast to the super-externalist and "super-Whorfian" (Chomsky 2000), we can imagine their nemesis: the super-internalist. This is something that Donnellan (1983) effectively does, albeit inadvertently. Imagine an advanced community whose residents regard chemical isotopes in such high esteem as to postulate that $\mathrm{H}_{2} \mathrm{O}$ and element 79 are totally independent objects from water and gold (effectively, the I-substances), such that they are in no way related. For instance, this community would consider heavy hydrogen and heavy water (or mineral water, salt water, distilled water...) not as different instances of complexes involving hydrogen and $\mathrm{H}_{2} \mathrm{O}$, but rather as distinct substances altogether. This scenario is also, of course, compatible with an externalist position, yet we can also consider this to be ground zero for the super-internalist, whereby the English word 'water' necessarily has no possible relation to chemical substances of differing varieties. The more moderate version of semantic internalism that I have been reviewing here, however, assumes that material constitution may indeed factor as an essential component of our conceptions of water and gold (indeed, some 
material basis seems necessary), but that our representations of these entities assumes more of a complex grid-like structure, with different weights being afforded to different senses. Indeed, it was already understood in Braisby et al. (1996), reviewing work from experimental psychology, that "natural kind terms are not employed in an essentialist manner" (see also Hampton et al. 2007, Martí 2015, Nichols et al. 2015, Tobia et al. 2019). Again, this conspires somewhat with Putnam's (1975) observations about the substance XYZ on Twin Earth: Putnam has a legitimate point about the shifting possible ontologies of whatever substances we care to refer to using common nominals, but this is not a rebuttal of internalism, merely a contextualization. There seem to be no compelling reasons to assume the existence of rigid designators in the Putnamian or Kripkean sense for natural language (see also Lewis 1997), and, as mentioned, we should be wary of "the myth of the logically proper name" (Strawson 1952: 216). So too for Hobbes (1889): "Names are signs not of things but of our cogitations" and "conceptions".

Relatedly, consider the case of 'jade'. After initial usage framed this as being a natural kind of some type, it was subsequently revealed to be composed of two different substances (silicate minerals), jadeite and nephrite - something which has no implications for the validity of semantic internalism, and the lexicon treats it the same as 'gold', albeit with the additional knowledge that its material basis can be said to be more complex than gold. By happenstance, the letter ' $\mathrm{J}$ ' is the only letter not currently occupying the periodic table. Imagine that scientists discover in ten years from now that the two elements that jade is composed of turn out to be derived from of a single, more fundamental element, J. Hence jade can once more be neatly packaged into a convenient word-object reference-but again, with no implications for the validity of the claim that 'jade' is a mind-internal lexical representation.

Other attempts to cling to externalist intuitions seem to meet with further problems. For instance, Russell's claim that objecthood is based on spatiotemporal contiguity cannot be sufficient: The four legs of a dog could be seen as a single object under many conceivable contexts, such as if they were cut off, tied together and used as a doorstop, still being understood by its user to be part of a dog. Abstract objects do not bear causal relationships and are not spatiotemporally located (an 'object' is also usually understood to be a concrete thing, hence the confusion when some are denied spatiotemporal relations). Peculiar Gestalt properties are afforded to us via our cognitive faculties, not through extra-mental components that we become, somehow, in accord with. Meaning never leaves the head: It is not "preserved, or transmitted, between speakers and over time" (Speaks 2010: 244); it is a cognitive 
phenomenon. Indeed, we cannot faithfully say with the externalist that meaning isn't in the head until we have explored what is meant by 'head'-we have no reason to assume that neural matter, delimited strictly by the skull, is incompatible with the ability to generate all possible linguistic meanings and interactions with the world.

Larger concerns loom beyond the single word level. Consider Braun and Saul's (2002) notorious puzzle of the 'resistance to substitution in simple sentences'. Initially, this puzzle collapses both 'belief' and meaning, since (3a) seems true while ( $3 b$ ) seems wrong, and should in turn lead back to the falsehood of (3a), given that Batman is Bruce Wayne, resulting in another tense standoff between language and reference - or between the mind and its nemesis, the external world:

(3) a. Batman fights more mobsters than Bruce Wayne.

b. Batman fights more mobsters than Batman.

Yet, when examined through a cognitive lens - a psycholinguistic lens-we see that there is a constraints on discourse interpretation in language through which whenever there are two referential expressions in a single clause, they are default interpreted as non-identical (redundant computation), and as such reference is obviative (Hinzen 2007). The sentence in (3b) forces us to search for different referents, when the formatives indicate only one entity.

We spend our time well when we consider how much of human thought-including linguistically encoded and encodable thought — relies on abstract objects, far removed from perceptual categorization, such as happiness, pain, fairness, truth and numbers. The major paradoxes in the philosophy of language literature only seem to arise with a certain class of words: those that provide concepts/perspectives which align closely with structures from physical theory. Thus 'water' and 'ship' and 'person' can participate in endless paradoxical scenarios, but 'plank' and 'buddy' do not seem as susceptible to philosophical inquiry, generating only ordinary perspectives rather than technical ones (Jackendoff 2012).

More recent frameworks can also be scrutinized in this light. The development of twodimensional semantics (which distinguishes between a word's primary and epistemic intension, and for many theorists is an internalist venture) presupposes a word-object reference relation, in which 'water' is treated as "a singular term referring to a chemical kind" (Byrne \& Pryor 2006: 38). Two-dimensional semantics works on the assumption that, "[s]ince it is not a priori that water is $\mathrm{H}_{2} \mathrm{O}$, there is an epistemic possibility in which water is, say, XYZ, and not $\mathrm{H}_{2} \mathrm{O}$, even though there is no such metaphysical possibility" (Ibid. 41). But this cannot be the 
case, since the concept of water carries no ontological presuppositions, unlike $\mathrm{H}_{2} \mathrm{O}$. There are simply concepts or representations, neither of which are of anything except themselves, making talk of "reference via causal-historical chains" (Russell 2010: 190) incoherent. 'Water' and ' $\mathrm{H}_{2} \mathrm{O}$ ' also seem to be objects from distinct Wittgensteinian language games: the former is a part of ordinary language, the latter is a technical concept requiring a particular theoretical apparatus for understanding. As such, ordinary lexical items like 'water' permit the generation of particular inferences and perspectives, or hypotheses about possible states of affairs, perceptions, or relations between objects. For the semantic internalist, lexical items are effectively hypotheses about the world; they do not host some extra-mental property that the language system independently investigates. Every time we use a particular concept in a new discourse, we invoke these hypotheses and, effectively, engage in a form of world-making, constructing freely a range of possible referents and qualities attributed to them and events in which they may play a role- but we do not establish some relation with the external world. Every conversation has a kind of mythopoetic status, invoking highly abstract representations even when referring to superficially simple notions like old books and water bottles and small towns and delayed lunches. Ordinary language use is much more akin to constructing fairy tales than it is to establishing mind-world connections.

Language is "first and foremost a combinatorial system", according to Spelke (2010: 208), which "may serve as a medium for constructing new concepts once words and expressions are linked to representations from multiple core systems. These combinations, in turn, make available a new range of potential actions". But, as I have argued, relying purely on intuitions concerning linguistic meaning is not in line with standards of scientific practice we uphold for any other domain in cognitive science.

\section{I Heard You Paint Houses}

"Astrophysicists must reckon with the possibility that their outer world is only our inner world turned inside out" (Lewis Mumford, cited in Arendt 1977: 167).

Recent empirical work has sought to address some of these issues concerning internalism/externalism. Haukioja et al. (2020) conducted a series of experiments showing that people use both appearance and underlying identity when defining a selection of five natural kind terms, depending on which aspect is highlighted as being novel: 'water', 'lightning', 'gold', 'diamond' and 'tiger'. The authors say that this shows both externalism and internalism 
face problems. Indeed, they argue that " $[\mathrm{b}]$ oth externalist and internalist theories have assumed that the extensions of our natural kind terms have sharp boundaries", which is contrary to the internalist positions in Pietroski (2018), Chomsky (2000), McGilvray (2005) and elsewhere. These results seem to show that different conceptual demands are at play depending on the scenario presented to participants - indeed, internalism would not have been proven right if material constitution was shown to be irrelevant, and nor would externalism have been proven right if speakers wholly deemed material constitution the sole determining property of water (see Cohnitz \& Haukioja 2020). In addition, the underlying assumption seems to be that guaging English speaker's judgements about 'water' directly exposes the facts of the matter. Psycholinguistic investigations are crucial, of course, but they do not address the more fundamental question: do words refer to the world, or not? Indeed, Haukioja et al. (2020) found that " $\mathrm{H}_{2} \mathrm{O}$ with a completely nonwatery appearance was consistently categorized as not being water", seeming to highlight the internalist position (though conflicting evidence was also found). As the authors themselves note, the results are possibly compatible with a causal homeostasis view of natural kind concepts, whereby deep and superficial properties cannot be separated (Rehder \& Kim 2010).

The authors are in fact concluding something already known to Aristotle: objects have distinct features, with different weightings based on the given object. Some are weighted more to material constitution, others to more abstract properties. Aristotle pointed out in his Metaphysics that the form of a house (its wood and stones) differs from its function (although he was making claims about what a house is supposed to really be, mind-externally, rather than conceptually). He realised that material constitution — or "the facts of the universe" (Carnap 1956: 11) - is only one factor we take into account when deciding what an object in the world is. Many other have been entertained in recent work (Pustejovsky \& Batiukova 2019), building on Aristotelian aitiational semantics, attempting to explore the explanations/causes for objecthood.

Keeping with this theme, if we use Chomsky's (2000) example of painting a house red, it seems to be understood, a priori, that it is the exterior surface of the house that is painted, not the interior, reflecting in part an underlying CONTAINER concept (but see Mukherji 2010 for different judgements, still from an internalist perspective).

(4) John painted the house red. 
If John's partner asks him 'Could you please paint the house red today?', expecting a redecorated living room and bedroom, they would be quite surprised arriving home and seeing that John had instead painted the external surface. This particular way we look at the world is shaped by specific linguistic functions interacting with higher-order vision. This is because "the semantic features impose an analysis in terms of specific properties of intended design and use, a designated exterior, and indeed far more intricacy. [...] The exterior-interior dimension has a marked and unmarked option; if neither is indicated, the exterior is understood" (Chomsky 2000: 125). The same also applies to any container word, like 'box' or 'helicopter'. The phrase 'My empty house' refers exclusively to the interior, with 'My house is gone' suggesting the abstract, non-concrete nature of the object (Hinzen: 2006: 259). Furthermore, a house is more than just its surface. If John is stood outside, 5 metres from the house, and Mary is stood inside, 5 metres from the surface, John is "near" the house, but Mary is not (Chomsky 2000). McGilvray (2005: 214) elaborates: "If in a cave and looking at its side, one is looking at the side of the cave, not a side of the mountain it is in. To look outside the cave at a mirror that reflects the outer surface of the mountain is, however, to look at the mountain's side". Even a construction such as "I painted the spherical cube red" is understood as the exterior surface being painted, and not the interior surface, despite the non-existence of this impossible, invented entity (Chomsky 2000: 35, 2007). The spherical cube also has a designated interior and exterior, as the person standing near the spherical cube is positioned outside it, not inside. Surveying other evidence, Chomsky (1996: 21) concludes that, "[o]ver a large range of cases, we think of an object somehow as its exterior surface, almost like a geometrical shape".

Further, it is not just the meaning of 'house' that is problematic for externalism: even colour words like 'red' in 'red house' raise similar extensional problems. How can we specify the supposed extension of 'red'? Proffering 'the set of all red things' does not help the matter: not all portions of a red thing are necessarily red, as the 'red house' (red outside) or 'red cave' (red inside) example shows. While red ink is red through and through, red food does not need to be. Extensions are not needed: all that is needed is some mind-internal representation of 'red', which can be linguistically encoded, and accessed by other cognitive systems (of which there are many, hence the large number of things we can deem 'red') in particular contexts of use (Pietroski 2018). seventeenth century: For him, an object is not "stamped or impressed upon the soul from 
without, but upon occasion of the sensible idea excited and exerted from the inward active and comprehensive power of the intellect itself" (1996: 91). It follows that these principles function the same way whether there's a city to visit or a house to paint or a bottle of water to drink or whether there's no world at all: a lexical item is "placed in an abstract space ... with its own organization that is only marginally influenced by the spatial relations in the real world" (Arsenijević 2008: 15). Whether or not there is some eternal referential relation inherent to the name 'Hamlet' makes no difference at all to our mental conception of Hamlet.

Language seems to provide (or at least encode lexically) function-related notions: a chair's shape and colour is plainly not something that language contributes, but its general use may be. We seem to have a deep, almost unshakeable intuition that concepts get their meaning from something outside the head. But this is just as baseless as our intuitions about mass, space and time, which have all been shattered by modern physics (and even the known laws of physics are not immune, of course, from being potentially shattered; Borsanyi et al. 2021). Indeed, what deserves to be investigated is the content of our referentialist intuition, and why it seems so prevelant. More broadly, "[t]here is [...] little evidence that 'intuition about meaning' is at all useful in the actual investigation of linguistic form" (Chomsky 1957: 94), and "[n]o area of linguistic theory is more veiled in obscurity and confusion" than semantics (Chomsky 1972: 75), and it remains unclear to what extent semantic properties of natural language expressions "belong to the language faculty as distinct from other faculties of mind" (Chomsky 2000: 129). For the Dutch physiologist Jacob Moleshott: "Except in relation to the eye, into which it sends its rays, the tree has no existence" (cited in Lange 1957: 41-42).

A central theme of Artistotle's philosophy - as distinct from the thought of Socrates and Plato - was that, "[a]s in human production and activity, for example in the building of a house or ship, the idea of the whole is always the first thing present as the end of the activity, and as this idea then, by the carrying out of the parts, realises itself in matter, nature must be supposed to proceed in the same way" (Lange 1957: 83-84, emphasis added). Aristotle's metaphysics, from this perspective, seems not so metaphysical after all, but rather more epistemological, almost anticipating Locke's distinction between primary and secondary qualities: The stone of a statue is the material, and the intended structure is the form, and both work in harmony to yield objecthood.

Externalists may reject these ideas by claiming that the word 'lion' must always refer to a lion, and not a camel (e.g., in the context of this debate: "'yarmulkes' does not refer to 
puppies, but instead refers to yarmulkes"; Paul \& Stainton 2009: 474). Indeed, 'lion' can be used to refer to things in the world that satisfy the individuation criteria for lion-ness, but that raises the question of what these criteria are, and the key internalist rebuttal is that we currently do not have such an externally-based, physically-instantiated set of criteria for even basic nominals like 'book' and 'tree'.

Moving beyond common objects like houses, even the use of deixis is not contingent on the existence of external objects, since we can say things like 'There is absolutely nothing right here'. Indeed, even the act of referring 'points' not to a presupposed object, but rather to some imposed geometrical surface: The directive 'Put your hat there' refers not to, say, a chair, but rather the abstract 'place' on top of it (Jackendoff 2012).

This lack of a formulable referential relation in natural language is highlighted further when we consider how it deals with the fact/fiction distinction. We can say that it is true that James Bond is British, and that it is false that he ever existed. The intended fictional/nonfictional status of a lexical item is irrelevant in terms of grammatical processes. The same linguistic (syntactic, computational) mechanisms are at play when we generate structures about fact or fiction. No language morphologically marks 'existence' the way is may mark animacy or tense. Inexistent entities, possible entities, fictional characters, objects no longer existing, and apparently simple objects which are actually impossible objects 'in disguise' (like 'lunch', via copredication) are all treated the same by syntax. It is somewhat peculiar that many philosophers have analysed fictional names as descriptions, but not real names.

Consider another property of apparent reference: Mary can falsely belief that the inventor of the telephone was Albert Einstein, and indeed this can be the only thing that Mary believes about Einstein, beyond her ability to recognize a photograph of him. When Mary says to John, "Einstein was a great man", Mary and John both seem to have true beliefs. After finding out that Mary's beliefs about Einstein are mistaken, it still seems reasonable for John to believe that Mary was nevertheless referring to the real Einstein when speaking about him. The intuition is that the property of inventing the telephone was incorrectly attributed, rather than Mary correctly having a belief about someone inventing the telephone and mistakenly switching the name Bell (or Gray, or Meucci, depending on how we define 'invent', which invites further complexity) for Einstein. This does not, however, prove that the name Einstein necessarily picks out the invariant individual born in Ulm on March $14^{\text {th }} 1879$. Rather, it exposes a pragmatic intuition about language use: John's I-language appears to default mark 
all reference to Einstein as referring to his own representation of this individual, rather than opening up a new, potential individual referent every time somebody talks to him about Einstein just in case this person has a false belief about who Einstein really was (which would be a massive computational burden). I think the same goes for many of the examples given in Kripke (1980), Putnam (1975) and elsewhere: They expose curious features of pragmatics, and conventionalised language use, but do not necessitate referentialism.

It seems that a 'house' is much more than its (i) material constitution and its (ii) function (as Aristotle assumed): we can also use its (iii) origin (Hobbes) or derive a sense of (iv) continuity (Locke's view of personhood, which can be shown to generalize far beyond humans) to individuate entities. In addition, we also have (v) extra-linguistic biases for shaping objecthood, as we have seen, pertaining to default marking of object surfaces. On top of (i)(v), we also have extra-lexical encyclopedic knowledge and prototypical instantiations, closely wedded to each content lexical item. The internalist can therefore assume that lexical items are instructions/directives to build concepts, and so any lexical item provides a directive to different cognitive modules, depending on its address: fetch concept from modules $\mathrm{X}$ and $\mathrm{Y}$ for 'house', but from modules $\mathrm{Y}$ and $\mathrm{Z}$ for 'newspaper', for instance, presumably cutting across the conceptual domains underpinning (i)-(v).

Consider a more concrete instantiation of this framework. Many of the world's languages (i.e., sufficiently overlapping I-languages) make use of quantification/numerosity (via a fronto-parietal network that seems closely linked to major language sites; Nieder 2016). On the other hand, they make little use of color, despite colour featuring just as prominently in ordinary experience. One of the possible reasons for this is that color concepts may be less easily fetchable due to the way that syntax happens to have interfaced with distinct cognitive modules (possibly due to the remoteness of occipital visual regions). For instance, one could construct an artificial language with some functional morpheme coding brightness of coloration. Likewise, language seems to make considerable use of certain contentful concepts (e.g., evidentiality) but not others (e.g., worry/sollicitativity) (Adger 2019, Peterson 2016). This may also be a case of language making (neurally) efficient use of specific representational resources to construct complex (monadic and dyadic) meanings (Murphy 2020b).

In the mean time, recent research has begun to investigate empirically the properties of extra-linguistic systems, which form part of the arsenal we bring with us when referring on any given occasion to a house (indeed, it seems possible to differentiate the distinct representations 
involved in 'house' only via direct and intentional contextual emphasis, or through our attentional apparatus). Consider the study conducted by Cheng et al. (2021), which concerns the cognitive neuroscience of object conceptualisation. The authors note that we think of ourselves as being 'inside' a scene but 'outside' an object, and speculate that one diagnostic feature of a scene may be concavity. This leads to the prediction that images depicting concavity will be behaviorally categorized as scenes more often than those depicting convexity, even if the images depict non-scenes. A second prediction is that the neural scene-processing network (including the parahippocampal place area, and occipital place area) will respond more to concave images than convex. Both predictions were realized. The authors also found no behavioral or neural differences between images of convex vs. concave buildings, but in a subsequent experiment they found a selective sensitivity to concavity over convexity of scene boundaries (such as walls) in these neural place areas. These results point to concavity as a diagnostic feature of visual scenes, providing an example of cognitive neuroscience shedding some light on long-standing problems in philosophy of language.

\section{Referring to Impossible Entities with Copredication}

There are objects in the world, we say. Thus far, I have argued that this and other externalist intuitions fail to capture lexical properties of a small number of common nominals, but in this final section I will brielfy turn to a class of lexical items that have also been systematically categorised and investigated: complex polysemous nominals (Apresjan 1974, Murphy 2021c, Ortega-Andrés \& Vicente 2019, Pustejovsky 1995, Ostler \& Atkins 1992). This concerns structures such as the following (see also (1) above):

(5) The book was interesting but in poor condition.

(6) The White House was repainted and issued a statement concerning taxes.

We can access multiple senses of 'book' and metonymic organizational expressions like 'the White House' simultaneously, yet nothing in the physical world can satisfy the conditions of being, for instance, simultaneously a unit of information and a collection of pages. This phenomenon of jointly associating multiple senses to a single expression is termed copredication (Murphy 2021a).

Consider how the counting properties and related individuation criteria do not permit an easy mapping onto externalist assumptions. Imagine there is a coffee table with five physical 
newspapers: two copies of Monday's Guardian, one copy of Tuesday's Independent, one copy of Wednesday's Times, and one copy of Thursday's Times. Depending on which representation we attend to, we could count five (PHYSICAL), four (INFORMATION) or three (INSTITUTION) entities.

The form of polysemy that generates copredications has not been given a satisfactory treatment in the externalist literature (for careful analysis, see Gotham 2016, 2020). Copredication has been called "a strange phenomenon" by an externalist philosopher in a recent analysis (Vicente 2021); an outlier, a weird and peculiar feature of language. But, on the contrary, copredication is precisely what one would deem readily permissable via semantic internalism. Under internalism, there are no mind-independent extensional constraints on reference, and the full extent of our linguistically-accessible conceptual apparatus measures the extent of our referential capabilities. Reacting to such copredications ('Lunch was delicious but took forever'; 'The oldest newspaper in New York regularly contains many good reports but some typos', etc.), most authors have tried to accommodate this phenomenon within a referentialist/externalist framework, but as Vicente (2021) reviews, these all have a number of issues (although Vicente also comes to an externalist conclusion). Pietroski (2018), Chomsky (2000), Yalcin (2014) and Murphy (2021a) maintain that the phenomenon may require abandoning referential semantics altogether, as maintained here. Internalists point to the centrality of human functional interests and concerns in linguistic reference, undermining the view that these nominals are a mereological sum (forming a 'complex object' in the mindindependent world) or a union of the extensions of different senses. Noun Phrases involving copredication simply do not refer to a stable, singular denotation, but instead provide multiple perspectives jointly pertaining to different features of discourse. The goal with copredication is to say something simple about something rather complex, and not to generate clear uniformity in referential scope.

While the focus of the present discussion has been on nominals, notice that verbs also generate copredications:

(7) Doctor Smith writes well but illegibly.

This eventive description can simultaneously refer to a process and a product. While copredications can also arise via verbs, it seems possible (Levin \& Rappaport Hovav 2013, Pietroski 2018) that verbs encode only thin, schematic meanings to be filled by rich nominal representations. For instance, consider the adicity requirements of verbs: 'run' only requires 
one argument, while 'give' seems to require three arguments to satisfy its selectional criteria (Pietroski 2008). Certain polysemous concepts exhibit a semantic structure which assumes the form of a set of clustered and overlapping interpretations. For example, (8) contains a number of clustered senses being attributed to a single nominal. This supports the claim that institutional copredications are not simply metaphors extending over institutional readingsas argued by Bahramian et al. (2017) — since semantically distinct senses can be attributed to school without relative loss of acceptability compared to supposedly non-metaphorical cases of genuine polysemy.

(8) The school with large windows starts at 9am and has a strict headmaster and unruly students.

While the discussion of copredication here has been much too brief (for a recent perspective on the counting paradoxes, see Gotham 2020), my aim has been to marshall a range of evidence in support of an internalist perspective on lexical meaning. We have seen that nominals can readily encode a range of potential perspectives on experience, and these perspectives are categorically mismatched such that one precludes the other, leading to the suggestion that such nominals have no uniform semantic value (Collins 2017). Referential invariance is not a property of nominals, and any such reference that does occur is an action and choice. Consider also how the word 'planet' originally included the Sun but excluded the Earth, but I assume that the common concept of ORBITING SPHEROID has not fundamentally shifted since heliocentric days, merely its range of possible choice of referent for human usage.

We should be suspicious, then, of externalist arguments that use clarity of linguistic coherence as evidence of some kind of independent referentialist relation, since all it signals is that the language system can generate such and such a representation (often due to pragmatic factors). For example, we can generate the interrogative expression 'Why do things happen?', which is a coherent expression, but this does not commit us to the idea that there is an actual question associated with this expression (it has no imaginable, meaningful answer; it is a pseudo-question; Chomsky 2000: 19). The structure has the form of an interrogative, but it is not a question, just as how certain lexical items act in discourse as if they refer to a coherent entity ('house', 'ship'), but there is no such object out there.

In summary, it seems that complex polysemy ultimately lies at many of the issues discussed in this article, from the controversies on Twin Earth to the problems faced by Theseus's competing ships to the judgements made about re-building demolished homes. 
Copredication is the most direct way to elucidate the type mismatch argument (Ludlow 2003) against externalism; that language can readily commit us to talking about things that markedly differ from that types of things we actually mean to speak about.

\section{Conclusion}

I have argued against the alleged determining influence of physicalism when fixing the meaning of so-called natural kind terms, and have defended the internalist position that it is the behaviour of the linguistic mind that give rise to even the simplest 'things', from water to books to trees to houses. This is not to retreact into vulgar linguistic idealism or some version of Machian thought (e.g., only experiential "phenomena" are real) — it is simply to acknowledge the fundamental role that language has in structuring our perspective of the mind-external world. What philosophers typically define as "the problem of the external world" (Neta 2003), or somesuch formulation, becomes not a purely metaphysical question, but a cognitive and naturalistic one. Under a certain form of semantic internalism, the problem (very informally) becomes how to alter one's prior representations/inferences as minimally as possible under current perceptions, so as to match the data of sense. The external world may be an inconvenience, but it is not a "problem". The very notion of semantic externalism qua Putnam is deeply at odds with how major currents in the brain sciences view organic worldly interactions (Ramstead et al. 2019, 2020), defying Darwin's principle of accounting for properties of "the citadel".

Chomsky will occasionally claim — as he did in a recent conversation with Kripke (Chomsky 2021) - that reference is only achieved if a word refers to something that a physicist could examine, which is something of an extreme characterture of externalism, but the general argument stands, as I have tried to show here. And Kripke will rebut, as he did to Chomsky, that when we discuss the intricate properties of 'river' and 'house' and the many factors that seem to conspire to determine possible individuation, that we are in fact not denying that these words have extensions, only that the extensions happen to be very complicated. I see this as a legitimate response from externalists, but one which brings with it an enormous amount of baggage, in addition to the inherently cognitively implausible feature of complex extensions for 'river' and 'house' and 'school' somehow being set during language acquisition. Assuming extensions is purely a stipulation, which we can eliminate from our theory of natural language 
via simple recourse to polysemous mental representations. Mental representations are useful fictions (Ramstead et al. 2020) for achieving particular inferential goals.

In response to the kind of internalist arguments made here, there have been surprisingly few responses from externalist (truth-conditional) semanticists (but see Cappelen \& Lepore 2005, Hansen 2018, King 2018). Semantic internalism reinforces some conclusions, of Newton, Locke, Hume, Russell and others: that the world is ultimately unknowable, and that only certain properties of the world are knowable (somehow) via convergence with properties of the mind, and so what we can express through words and sentences can only capture a narrow component of this confined level of understanding.

As Darwin argued, we cannot faithfully explore the products of the mind (including language) without giving some regard to its physical, cognitive architecture. We cannot speak of extensions and denotations and meta-semantics unless we have a clear understanding of what the mechanics of the mind are. We can then choose to pursue invented systems of mathematics and formal language, with their own constructed properties, so long as we are careful not to confuse such artificial systems with natural language, a biological object. I have defended the claim that the mechanics of mind generate internal representations that signal to other language-external cognitive systems particular, possible interpretations, with these language-external systems in turn providing certain biases for these interpretations (i.e., concave/convex CONTAINER concepts). These mechanics, in effect, make reference to other cognitive domains - but they do not appear to deem the external world fit for such referential treatment.

\section{References}

ADGER, D. (2019). Language Unlimited: The Science Behind Our Most Creative Power. Oxford: Oxford University Press.

APRESJAN, J. (1974). Regular polysemy. Linguistics 14: 5-32.

ARENDT, H. (1977). The Life of the Mind. London: Harcourt.

ARSENIJEVIC, B. (2008). From spatial cognition to language. Biolinguistics 2(1): 3-23.

BAHRAMIAN, H., Nematollahi, N., \& Sabry, A. (2017). Copredication in homotopy type theory. Ms. Indiana University Bloomington.

BORSANYI, S., Fodor, Z., Guenther, J.N., Hoelbling, C., Katz, S.D., Lellouch, L., Lippert, T., Miura, K., Parato, L., Szabo, K.K., Stokes, F., Toth, B.C., Torok, Cs., \& Varnhorst, L. 
(2021). Leading hadronic contribution to the muon magnetic moment from lattice QCD. Nature https://doi.org/10.1038/s41586-021-03418-1.

BRADDON-MITCHELL, D. (2004). Masters of our meanings. Philosophical Studies 118(12): $133-152$.

BRAISBY, N., Franks, B., \& Hampton, J. (1996). Essentialism, word use, and concepts. Cognition 59: 247-274.

BRAUDEL, F. (1992). Civilization and Capitalism 15th-18th Century, Volume I: The Structures of Everyday Life: The Limits of the Possible. Translated by Siân Reynold. University of California Press.

BRAUN, D., \& Saul, J. (2002). Simple sentences, substitution, and mistaken evaluations. Philosophical Studies 111(1): 1-41.

BURGE, T. (1979). Individualism and the mental. Midwest Studies in Philosophy 4(1): 73122.

BYRNE, A., \& Pryor, J. (2006). Bad intentions. In M. García-Carpintero \& J. Macià (Eds.), Two-Dimensional Semantics (pp. 38-54). Oxford: Oxford University Press.

CARNAP, R. (1956). Meaning and Necessity: A Study in Semantics and Modal Logic. University of Chicago Press.

CARSTON, R. (2004). Explicature and semantics. In S. Davis \& B.S. Gillon (Eds.), Semantics: A Reader (pp. 817-845). Oxford: Oxford University Press.

CHENG, A., Walther, D.B., Park, S., \& Dilks, D.D. (2021). Concavity as a diagnostic feature of visual scenes. NeuroImage 232: 117920.

CHOMSKY, N. (1957). Syntactic Structures. The Hague: Mouton.

CHOMSKY, N. (1972). Studies on Semantics in Generative Grammar. The Hague: Mouton.

CHOMSKY, N. (1996). Powers and Prospects: Reflections on Human Nature and on the Social Order. Boston: South End Press.

CHOMSKY, N. (2000). New Horizons in the Study of Language and Mind. Cambridge, MA: MIT Press.

CHOMSKY, N. (2007). 'On referring' revisited. Lecture at Harvard University, 30 October.

CHOMSKY, N. (2021). Invited lecture at the Rule Following and Normativity class, Spring. Saul Kripke Center. The Graduate Center, CUNY.

COETZEE, J.M. (2000). Disgrace. London: Vintage.

COETZEE, J.M. (2020). The Death of Jesus. New York: Viking.

COHNITZ, D. \& Haukioja, J. (2020). Variation in natural kind concepts. In Å. Wikforss \& T. Marques (Eds.), Shifting Concepts. Oxford: Oxford University Press.

COLLINS, J. (2017). The copredication argument. Inquiry 60(7): 675-702.

CUDWORTH, R. (1996). A Treatise Concerning Eternal and Immutable Morality. S. Hutton (Ed.). Cambridge: Cambridge University Press. 
DAVIDSON, D. (1984). Truth and meaning. Truth and Interpretation. Oxford: Oxford University Press.

DESCARTES, R. (1984). Comments on a Certain Broadsheet. In J. Cottingham, R. Stoothoff \& D. Murdoch (Trans.), The Philosophical Writings of Descartes. Vol. I. Cambridge: Cambridge University Press.

DONNELLAN, K.S. (1983). Kripke and Putnam on natural kind terms. In C. Ginet \& S. Shoemaker (Eds.), Knowledge and Mind (pp. 84-104). Oxford: Oxford University Press.

DUMMETT, M. (1986). A nice derangement of epitaphs: some comments on Davidson and Hacking. In E. Lepore (Ed.), Truth and Interpretation (pp. 459-476). Oxford: Blackwell.

ELBOURNE, P. (2011). Meaning: A Slim Guide to Semantics. Oxford: Oxford University Press.

GERTLER, B. (2012). Understanding the internalism-externalism debate: what is the boundary of the thinker? Philosophical Perspectives 26(1): 51-75.

GOTHAM, M. (2016). Composing critiera of individuation in copredication. Journal of Semantics 34(2): 333-371.

GOTHAM, M. (2020). Property inheritance, deferred reference and copredication. Ms. University of Oxford. https://semanticsarchive.net/Archive/WRhMjkxN.

GOULD, S.J. (1975). Review of Evolution of the Brain and Intelligence by Harry J. Jerison. Paleobiology 1(1): 125-129.

HAMPTON, J.A., Estes, Z., \& Simmons, S. (2007). Metamorphosis: essence, appearance and behaviour in the categorization of natural kinds. Memory \& Cognition 35: 1785-1800.

HANSEN, N. (2018). Just what is it that makes Travis' examples so different, so appealing? In J. Collins \& T. Dobler (Eds.), The Philosophy of Charles Travis (pp. 113-134). Oxford: Oxford University Press.

HAUKIOJA, J., Nyquist, M., \& Jylkkä, J. (2020). Reports from Twin Earth: both deep structure and appearance determine the reference of natural kind terms. Mind \& Language https://doi.org/10.1111/mila.12278.

HEMPEL, C. (1950). Problems and changes in the empiricist criterion of meaning. Revue Internationale de Philosophie 4(11): 41-63.

HIGGINBOTHAM, J. (1990). Contexts, models, and meanings: a note on the data of semantics. In R. Kempson (Ed.), Mental Representations: The Interface Between Language and Reality (pp. 29-48). Cambridge: Cambridge University Press.

HINZEN, W. (2006). Mind Design and Minimal Syntax. Oxford: Oxford University Press.

HINZEN, W. (2007). An Essay on Names and Truth. Oxford: Oxford University Press.

HOBBES, T. (1889). The English Works of Thomas Hobbes of Malmesbury, Vol. I. W. Molesworth (Ed.). London: Bohn.

HOFFMAN, J., \& Rosenkrantz, G.S. (2003). Platonic theories of universals. In M.J. Loux \& D.W. Zimmerman (Eds.), The Oxford Handbook of Metaphysics (pp. 46-74). Oxford: Oxford University Press. 
HORNSTEIN, N., \& Anthony, L. (2003). Introduction. In L.M. Anthony \& N. Hornstein (Eds.), Chomsky and His Critics (pp. 1-10). Oxford: Blackwell.

HUME, D. (1739-40/1978). A Treatise of Human Nature. L. A. Selby-Bigge (Ed.), 2nd ed. Oxford: Clarendon.

JACKENDOFF, R. (1972). Semantic Interpretation in Generative Grammar. Cambridge, MA: MIT Press.

JACKENDOFF, R. (2012). A User's Guide to Thought and Meaning. Oxford: Oxford University Press.

JOHNSTON, M., \& Leslie, S. (2012). Concepts, analysis, generics and the Canberra Plan. Philosophical Perspectives 26(1): 113-171.

JUHL, C., \& Loomis, E. (2010). Analyticity. London: Routledge.

KATZ, J., \& Fodor, J. (1963). The structure of a semantic theory. Language 39: 170-210.

KENNEDY, C., \& McNally, L. (2010). Color, context, and compositionality. Synthese 174: 79-98.

KING, J.C. (2018). W(h)ither semantics!(?). Nous 52: 772-795.

KRIPKE, S.A. (1979). A puzzle about belief. In A. Margalit (Ed.), Meaning and Use (pp. 239283). Dordrecht: D. Reidel.

KRIPKE, S.A. (1980). Naming and Necessity. Cambridge, MA: Harvard University Press.

KRIPKE, S.A. (2019). Naming and Necessity revisited. Centre for Logic and Language Special Lecture. Institute of Philosophy, University of London. 30 May.

LANGE, F.A. (1957). The History of Materialism and Criticism of its Present Importance. Translated by Ernest Chester Thomas. 3rd ed. London: Routledge \& Kegan Paul.

LEPORE, E. (2001). Donald Davidson. In A.P. Martinich \& D. Sosa (Eds.), A Companion to Analytic Philosophy (pp. 296-314). Oxford: Blackwell.

LEVIN, B., \& Rappaport Hovav, M. (2013). Lexicalized meaning and manner/result complementarity. In B. Arsenijević, B. Gehrke, \& R. Marín (Eds.), Subatomic Semantics of Event Predicates (pp. 49-70). Dordrecht: Springer.

LEWIS, D. (1975). Languages and language. In K. Gunderson (Ed.), Language, Mind, and Knowledge (pp. 163-188). University of Minnesota Press.

LEWIS, D. (1997). Naming the colours. Australasian Journal of Philosophy 75: 325-342.

LUDLOW, P. (2003). Referential semantics for I-languages? In L.M. Anthony \& N. Hornstein (Eds.), Chomsky and His Critics (pp. 140-161). Oxford: Blackwell.

LUDLOW, P. (2014). Living Words: Meaning Underdetermination and the Dynamic Lexicon. Oxford: Oxford University Press.

MARTI, G. (2015). General terms, hybrid theories and ambiguity: a discussion of some experimental results. In J. Haukioja (Ed.), Advances in Experimental Philosophy of Language (pp. 157-172). London: Bloomsbury Academic. 
MEINONG, A. (1904). The theory of objects. In R. Chisolm (Ed.), Realism and the Background of Phenomenology. New York: Free Press. 1960.

MCGILVRAY, J. (2005). Meaning and creativity. In J. McGilvray (Ed.), The Cambridge Companion to Chomsky (pp. 204-222). Cambridge: Cambridge University Press.

MUKHERJI, N. (2010). The Primacy of Grammar. Cambridge, MA: MIT Press.

MURPHY, E. (2020a). Language design and communicative competence: the minimalist perspective. Glossa: A Journal of General Linguistics 5(1): 2.

MURPHY, E. (2020b). The Oscillatory Nature of Language. Cambridge: Cambridge University Press.

MURPHY, E. (2021a). Linguistic Representation and Processing of Copredication. $\mathrm{PhD}$ dissertation. University College London.

MURPHY, E. (2021b). Persistence conditions of institutional entities: Investigating copredication and prototypicality through a forced-choice experiment. Frontiers in Psychology https://www.frontiersin.org/articles/10.3389/fpsyg.2021.528862/abstract.

MURPHY, E. (2021c). Predicate order and coherence in copredication. Inquiry https://doi.org/10.1080/0020174X.2021.1958054.

NETA, R. (2003). Contextualism and the problem of the external world. Philosophy and Phenomenological Research 66(1): 1-31.

NICHOLS, S., Pinillos, A. \& Mallon, R. (2015). Ambiguous reference. Mind 125: 145-175.

NIEDER, A. (2016). The neuronal code for number. Nature Reviews Neuroscience 17: 366382.

ORTEGA-ANDRES, M., \& Vicente, A. (2019). Polysemy and co-predication. Glossa: A Journal of General Linguistics 4: 1.

OSTLER, N., \& Atkins, B.T. (1992). Predictable meaning shift: Some linguistic properties of lexical implication rules. In J. Pustejovsky \& S. Bergler (Eds.), Lexical Semantics and Knowledge Representation (pp. 87-100). Berlin: Springer-Verlag.

PAUL, I., \& Stainton, R.J. (2009). Review of An Essay on Names and Truth. Mind 118: 471475.

PETERSON, T. (2016). Mirativity as surprise: evidentiality, information, and deixis. Journal of Psycholinguistic Research 45(6): 1327-1357.

PIATTELLI-PALMARINI, M. (2020). Minds with meanings (pace Fodor and Pylyshyn). Rivista Internazionale Di Filosofia e Psicologia 11(1): 1-18.

PIETROSKI, P. (2008). Minimalist meaning, internalist interpretation. Biolinguistics 2(4): $317-341$.

PIETROSKI, P. (2017). Semantic internalism. In J. McGilvray (Ed.), The Cambridge Companion to Chomsky (pp. 207-227). $2^{\text {nd }}$ edition. Cambridge: Cambridge University Press.

PIETROSKI, P. (2018). Conjoining Meanings: Semantics Without Truth Values. Oxford: Oxford University Press. 
PUSTEJOVSKY, J. (1995). The Generative Lexicon. Cambridge, MA: MIT Press.

PUSTEJOVSKY, J., \& Batiukova, O. (2019). The Lexicon. Cambridge: Cambridge University Press.

PUTNAM, H. (1975). The meaning of 'meaning'. In K. Gunderson (Ed.), Language, Mind and Knowledge (pp. 131-193). Minneapolis: University of Minneapolis Press.

PUTNAM, H. (1992). Replies. Philosophical Topics 20: 347-408.

RAMSTEAD, M.J.D., Kirchhoff, M.D., Constant, A., \& Friston, K.J. (2019). Multiscale integration: beyond internalism and externalism. Synthese DOI: 10.1007/s11229-01902115-x.

RAMSTEAD, M.J.D., Friston, K.J., \& Hipólito, I. (2020). Is the free-energy principle a formal theory of semantics? From variational density dynamics to neural and phenotypic representations. Entropy 22: 889. 1-30.

REHDER, B., \& Kim, S. (2010). Causal status and coherence in causal-based categorization. Journal of Experimental Psychology: Learning, Memory and Cognition 36(5): 1171-1206.

RUSSELL, B. (1905). On denoting. Mind 14: 479-493.

RUSSELL, B. (2003). Russell on Metaphysics: Selections from the Writings of Bertrand Russell. S. Mumford (Ed.). London: Routledge.

RUSSELL, G. (2010). Analyticity in externalist languages. In S. Sawyer (Ed.), New Waves in Philosophy of Language (pp. 186-205). London: Palgrave Macmillan.

SMITH, B. (1992). Understanding language. Proceedings of the Aristotelian Society 109-141.

SPEAKS, J. (2010). Introduction, transmission, and the foundations of meaning. In S. Sawyer (Ed.), New Waves in Philosophy of Language (pp. 226-249). London: Palgrave Macmillan.

SPELKE, E. (2010). Innateness, choice, and language. In J. Bricmont \& J. Franck (Eds.), Chomsky Notebook (pp. 203-210). Columbia University Press.

STRAWSON, G. (2008). Real Materialism and Other Essays. Oxford: Oxford University Press.

STRAWSON, G. (2009). The self. In B.P. McLaughlin, A. Beckermann \& S. Walter (Eds.), The Oxford Handbook of Philosophy of Mind (pp. 541-564). Oxford: Oxford University Press.

STRAWSON, P.F. (1950). On referring. Mind 59(235): 320-344.

TOBIA, K.P., Newman, G.E. \& Knobe, J. (2019). Water is and is not H2O. Mind \& Language. https://doi.org/10.1111/mila.12234.

UNDERHILL, J.W. (2009). Humboldt, Worldview and Language. Edinburgh: Edinburgh University Press.

VALENTE, M. (2019). Communicating and disagreeing with distinct concepts: a defense of semantic internalism. Theoria 85 : 312-336.

VICENTE, A. (2019). Chomskyan arguments against truth-conditional semantics based on variability and co-predication. Erkenntnis https://doi.org/10.1007/s10670-019-00138-x. 
THE CITADEL ITSELF: DEFENDING SEMANTIC INTERNALISM AFTER A BRIEF LUNCH IN A RED HOUSE

992 VICENTE, A. (2021). Approaches to co-predication: Inherent polysemy and metaphysical 993 relations. Journal of Pragmatics https://doi.org/10.1016/j.pragma.2021.02.007.

994 WELLWOOD, A., Hespos, S.J., \& Rips, L. (2018). How similar are objects and events? Acta $995 \quad$ Linguistica Academica 65: 473-501.

996 YALCIN, S. (2014). Semantics and metasemantics in the context of generative grammar. In A. Burgess \& B. Sherman (Eds.), New Essays in Metasemantics. Oxford: Oxford University Press. 